\title{
Attaining the Elusive: Efficacy, Math Education and Black and Latino Students
}

\author{
Gilberto Arriaza and Cesar Monterrosa \\ California State University, East Bay and Oakland Unified School District
}

\begin{abstract}
Low enrollment of Latino, African American, Native American, and Southeast Asian American students in science, technology, engineering, and math (STEM) classes, via advanced placement (AP) courses, remains a problem for high schools, and education leaders across the United States. More than just examining the factors behind this enrollment issue, we wanted to understand the focal factors underpinning success in AP courses of those few who do enroll. For that purpose, we grounded this case study on social cognitive theory's central variable of self-efficacy. We found that teacher facilitated experience plays a pivotal function in students' success in STEM education, more specifically, AP math.
\end{abstract}

Keywords: mathematics, efficacy, diversity

\section{INTRODUCTION}

ow enrollment of Latino, African American, Native American, and Southeast Asian American students in science, technology, engineering, and Math (STEM) advanced placement (AP) classes, remains a challenge for high schools across the United States (Brown \& Campbell, 2008; Klopfenstein, 2004; Lichten, 2007; Ndura, Robinson, 2003; Trounson \& Colvin, 2002). The impact of this issue can more immediately be felt on the dayto-day experience of youth in schools. In the long term, we fear this issue could have far reaching effects that impact economic security and, perhaps, the nature of the country's democratic system.

More than the factors behind the school system's enrollment failure, we wanted to understand the focal factors underpinning success in AP math courses of those few who do enroll. For that purpose, we grounded this study on social cognitive theory's central variable of self-efficacy. We followed Bandura's (1991) four factors defining self-efficacy: (a) Experience, (b) Modeling, (c) Social Persuasion, and (d) Physiological Factors. We explored these factors as sources of self-efficacy in terms of exposure to, or the lack of, the following six categories: early childhood education, family and community differences, expectations, exposure to advanced placement courses, stereotype threat, and socioeconomic status.

Thus, the research question was this: which of the four factors of self-efficacy (a) Experience, (b) Modeling, (c) Social Persuasion, and (d) Physiology - has the greatest impact on Latino and African American students enrollment in AP math courses? This paper first discusses the focal issue; second, it reviews the available literature; third, it defines the methodology guiding the study, fourth, the article shows the key findings, and then it closes with a set of conclusions.

\section{THE FOCAL ISSUE}

High schools with high concentrations of Latinos and African Americans massively fail to offer advanced placement (AP) courses (Zarate \& Pachon, 2006). When these high schools do offer advanced placement courses, very few students score proficient or better in the AP exams (Brownell, Furry, \& Beasley, 1999; Whiting \& Ford, 
2009). When youth attend schools in which Black and Latino make up the numerical majority, they tend to be underenrolled in said courses (Handwerk, 2008; Solorzano \& Ornelas, 2004). Yet, one of the main drivers of STEM education is the perceived lack of sufficient scientists and engineers entering the country's workforce which in turn, as Salzman \& Lowell (2007) have argued, threatens the United States' economic health and relevant position in global innovation. This workforce shortage appears worse among Black, Latino, Native American, and South-East Asian populations.

Whiting and Ford (2009), among others, have suggested a link between this under representation and a low offering of AP courses in schools, particularly serving low-income families, where these populations form the majority. Moreover, as Arellano \& Padilla (1996), and Gándara (2006) have shown, the lack of familiarity with crucial information - such as the prerequisites of AP courses, when to take SAT exams, how to apply for financial aid - plays a key role in explaining the low numbers of Blacks and Latinos in the AP track. Environments such as the ones so far described, may only engender a perpetual cycle of low tracking in math and science. But the fact that in these same environments students from these two communities still enroll and some even succeed, confirmed to us the need to look closely at self-efficacy, as a counter subjective force.

Although ample research (e.g. Pajares \& Kranzler, 1996; Pajares, 1995; Usher \& Pajares, 2006, 2008; Usher, 2009; Zeldin, Britner \& Pajares, 2008; Zimmerman, Badura \& Martinez Pons, 1992; Zimmerman, 2000) attests to the predictive power of self-efficacy - i.e. the sense of accomplishment and self-control - fewer studies have associated self-efficacy of underrepresented students to AP math and science courses. Some research has suggested that selfefficacy influences interests, goals, performance, and persistence (Eccles, 1994; Lent, Brown, \& Hackett, 1994). Additionally, building efficacy has directly been connected to self-regulation. As defined by Zimmerman (2002b) selfregulation denotes "the self-directive process by which learners transform their mental abilities into academic skills" (p. 65). Self-regulation, in other words, implies a metacognitive process that requires students to explore their own thought processes so as to evaluate the results of their actions, and plan alternative pathways to success.

\section{REVIEW OF THE LITERATURE}

Studies conducted by Murphy and Sullivan (1997) showed that in the mid-80s Latinos, African Americans, and Native Americans represented $20 \%$ of the total population of the United States but they embodied less than $7 \%$ of the employees in the fields of STEM related careers. These statistics have not significantly changed over time. Kendricks and Arment (2011) found that freshman STEM majors (social sciences excluded) made up $21.5 \%$ of all college freshmen in 2006. Of this group, about one of every five were African Americans. However, documenting the 2007 graduation statistics. Kendricks \& Arment (2011) showed that African Americans attained 7\% to 8\% of STEM bachelor's degrees compared to $64 \%$ of the Caucasian cohort. Efforts to uncover the potential governing factors of this issue have produced numerous studies, some of which we review below.

Researchers such as Green, Walker, Hoover-Dempsey, \& Sandler (2007), and Pomerantz, Grolnick, \& Price (2005) argue that a critical factor at play in low STEM fields representation of Latino and Black, possibly originates from low parent involvement in the early stages of the education processes of these populations. Klopfenstein (2004), Martínez Alemán (2006), and Whiting \& Ford, (2009) looked at the impact of family income on this issue. Klopfenstein (2004): indeed discovered that students in high-poverty and rural schools continue to have limited access to or be underrepresented in AP courses.

According to national academic performance data (National Center of Education Statistics, 2007), Latino children were less likely than other economically poor children to take part in early childhood development 
programs (e.g. Head Start). Martinez Alemán (2006), following national statistics, suggested that in the United States fewer than half (45.3\%) of Latino four-year-olds were enrolled in pre-primary education, as compared with almost sixty percent of White four-year-olds. Latino children, according to these national figures, were more likely to repeat grades than Whites. Although Latino nine-to-eleven-year-olds were as likely to be retained in grades as Whites, among older children (12-to-14-year-olds) 35.5\% Latinos were not promoted in grade. By the time Latino children were 15-to-17-years-old, forty percent risked being held back. Crucially, $6.4 \%$ of all Latino children nation-wide participated in advanced or "gifted" programs. Whites - who constituted $17 \%$ of the entire K-12 population in the country- accounted for eighty percent of the enrollment in these programs (Alemán, 2006).

Moreover, Solorzano \& Ornelas $(2002,2004)$ argue that race-based unequal access to both general education and to AP courses leaves Latino and Black students out of high track course-work. The authors detailed the lack of educational parity through cases where Latino students attended schools with high AP enrollment, but were generally not equitably represented, which amounted to what they labeled "schools within schools" (p. 15). In other words, the school as a whole, and the insidious presence of a segregated one within, existed. Similarly, Zarate \& Pachon, (2006) pointed out that economically depressed school districts typically offered far fewer AP courses, where only a handful of students scored proficient or better in AP exams. But low Latino and Black involvement in STEM fields may also originate in the school's treatment of these populations. Archbald, Glutting, \& Xiaoyu (2009), Flowers (2008), Rosenbaum, Miller, \& Krei, (1996) have explained that teachers and counselors convey expectations that deter African American and Latino students from placement in college preparatory or honors level courses. These expectations typically include non academic characteristics such as ethnicity, socioeconomic status, and even personality traits.

Furthermore, a lack of early education opportunities may also promote low student enrollment in advanced science and math courses in middle and high school (Dejarnette, 2012). The importance of early exposure to engineering courses at pre-K levels (Bagiati, Yoon, Evangelou, \& Ngambeki, 2010; Gándara, 2010), as well as the use of assessment to improve science education in preschool (Brenneman, 2011) holds great promise in redressing Black and Latino students' lack of AP involvement. Some researchers suggest that early education impacts social and academic performance over time (e.g. McWayne, Cheung, Wright \& Hahs-Vaughn, 2012; Pungello et al., 2010; Ramey et al., 2000); Brown \& Campbell (2008); Klopfenstein (2004); Lichten (2007); Ndura, Robinson, \& Ochs (2003b); and Trounson \& Colvin (2002) have shown that AP enrollment of Latino, Black, Native American, and Southeast Asian students remains largely below these groups' relative numbers. Not only do high schools with high concentrations of Latino and Black students continue to lag in their AP course offerings (Zarate \& Pachon, 2006), but also - as Brownell, Furry, \& Beasley (1999), and Whiting \& Ford (2009) uncovered - these schools show even fewer students scoring proficient or better in AP exams. In other words, underrepresented students attending schools in which they are in the majority, tend to still be underrepresented in AP courses.

Lastly, research exploring the relationship between self-efficacy and performance in math and science courses offers some clues to explaining what is not working and potential avenues to solve the issue. Studies conducted by Judge, Jackson, Shaw, Scott, \& Rich, (2007), Rittmayer \& Beier, (2008); H. Wang \& Pape, 2004; X. Wang, (2012) suggest that high school math achievement, exposure to math and science courses, and math self-efficacy beliefs, significantly affect students' intent to major in STEM fields, which in turn influences entrance into STEM majors. Given the knowledge thus far reviewed, and the focus of our research interest, we decided to follow social cognitive theory (SCT). More specifically we honed in on self-efficacy, a central tenet of SCT, as the key construct of our theoretical framework. 
According to Bandura (1991) self-efficacy contains four factors (a) experience, (b) modeling, (c) social persuasion, and (d) physiological factors. Bandura (1982) has shown that experiencing mastery is the most important factor positively affecting a person's self-efficacy, whereas failure lowers it. Students, the author shows, who perform well on math tests and earn high grades in math classes seem likely to develop a strong sense of confidence in their capabilities on this subject. Pajares (2002) uncovered that a sense of efficacy helps ensure that students enroll in subsequent math-related classes, approach math tasks with serenity, and increase their efforts when a difficulty arises. Starting with modeling we briefly examine each of the four factors. Modeling is experienced when one observes mastery in others and, consequently one's self-efficacy tends to increase, but when one sees failure occurring, one's self-efficacy tends to decrease (Bandura, 1982). The modeling process, the author notes, seems most effective when individuals see themselves as similar to the model they observe - teachers in our study's case. Although not as influential as direct experience, Pajares (2002) writes, when a highly regarded teacher models excellence in an academic endeavor or activity, students will more likely develop the belief that "I can do that".

Offering mentorship opportunities to students - such as internships, independent studies, enrichment programs, and dual-enrollment - and creating mentoring programs tailored to inform educators and practitioners about mentoring programs based on the needs of specific student populations, appear to hold strong potential benefits (Nora \& Crisp, 2012). Some results suggest, for instance, that visiting a counselor for college entrance information had a positive and significant influence on students' likelihood of postsecondary enrollment, and counseling-related effects were greatest for students from low socioeconomic status (Belasco, 2013). According to Bandura (1991) social persuasion generally manifests as direct encouragement or discouragement from another person. Discouragement may generally be more effective at decreasing a person's self-efficacy than encouragement might be at increasing it. Most adults can recall something that was said to them - or done to, or carried out for them during their childhood - that had a profound effect on their confidence throughout the rest of their lives (Pajares, 2002).

SCT allows for interventions to be designed in the classroom to improve student's learning (Rice, Lopez, Richardson, \& Stinson, 2013). Some studies suggest that one way to increase scores on standardized math tests is to increase students' math self-efficacy. Teachers can positively influence math self-efficacy (Judge et al., 2007) by creating a caring, challenging, and mastery-oriented environment in math and reading in elementary schools (Pianta, Belsky, Vandergrift, Houts, \& Morrison, 2008). Similarly, students who perceived their classroom environments as more caring, challenging, and mastery-oriented, had significantly higher levels of math self-efficacy than those in less caring, non-challenging, and non-mastery-oriented classrooms (Fast, Lewis, Bryant, Bocian, Cardullo, Rettig \& Hammond 2010).

\section{METHODOLOGY}

\section{Framework Design}

This study used a sequential mixed method to develop a rich description of four factors of self-efficacy - (a) Experience, (b) Modeling, (c) Social Persuasion, and (d) Physiological Factors - and their associated impact on Latino and African American entrance into AP math courses. Following Bandura (1986), these four factors involve the reciprocal interplay between cognitive, behavioral, and environmental forces. The sequential design sought to elaborate or expand on the findings of one method with another method (Creswell, 2009). Beginning with a survey method of 35 twelfth graders enrolled in AP calculus, the study followed with a detailed interview series of twelve, twelfth graders, enrolled in AP calculus. This was a convenience sample based on parental response to our request. 
Interview data were transcribed, coded, and analyzed according to the guidelines set forth by Hibbs (2012), and Usher (2009) and using the Hyper-RESEARCH program. A total of (N) 35 twelfth graders enrolled across three AP calculus courses and in two different high schools were first surveyed. From this convenience sample we selected twelve for a series of interviews; they were organized in five small focus groups with the intent to crossreference and triangulate the results of the survey. The survey questions for this study employed the intermediate degrees of assurance. The study also applied the Statistical Package for the Social Sciences (SPSS) to conduct a frequency analysis for each of the survey questions. In order to understand which variable contributed the most to the Latino and African American students' entry into AP calculus, we conducted a frequency analysis of each response by ethnicity.

\section{Setting}

This sequential mixed methods study took place in Urban Unified School District (UUSD), a large, comprehensive school district in northern California. It enrolled 37,040 students in the 2013-2014 school year. Of the seven high schools, two were selected for the study based on two criteria. The first one being the general geographical distinction: one school is set in "the hills", which serves a neighborhood that tends to be more affluent than the rest of the city, and the other located in "the flatlands", a generally economically depressed neighborhood. The second criteria was that the overall enrollment had to reflect the ethnic diversity of the school district's population.

\section{Participants}

All members of the final group of twelve participants were enrolled in AP calculus in twelfth grade: nine Latinos and three African American, across the two high schools. They were self-selected from the original thirtyfive, according to who returned the consent forms approved by themselves and by their parents. Through these interviews we wanted to elaborate and expand on the survey results from the 35 students in phase one. The twelve participants represented more than three quarters of the total Black and Latino AP enrollment across the two high schools as well as the total of four AP calculus courses offered.

\section{Instruments}

We explored the following question: Which of the four factors of self-efficacy - (a) Experience, (b) Modeling, (c) Social Persuasion, and (d) Physiological Factors - has the greatest impact on Latino and African American entry into AP math courses? These factors - redefined as variables - were operationalized considering gender and ethnicity throughout the survey, and interview questionnaire.

Following Bandura's (2006) notion that no all-purpose measure of perceived self-efficacy exists, we used the standard methodology for measuring self-efficacy; we listed items portraying different levels of task demands and asked participants to rate the strength of their belief in their ability to execute said items. We measured strength of efficacy beliefs on a 100-point scale, ranging in 10-unit intervals from 0 ("Cannot do") through intermediate degrees of assurance, 50 ("Moderately certain can do") to complete assurance, 100 ("Highly certain can do"). The semistructured interview protocol was adapted specifically for the Latino and African American participants. Similar protocol has been used by Zeldin and Pajares (2000), and Usher (2009). These protocols were designed to engage the participants in comprehensive discussion about the factors they considered important in order to further analyze similarities and differences of the survey results. These interviews were conducted with a total of four questions which set parameters, while still allowing for flexibility in terms of follow-up question. For example: "In the survey you rated your math ability on a scale of 1 to 10 . How would you rate your confidence in math?" 


\section{FINDINGS}

The salient role of experience - as a factor forging efficacy - throughout the study's data, lead us to report here the study results for this variable and its different components. We decided that the other three variables modeling, social persuasion, and physiological factors - needed separate attention. These emerged as insignificant forces shaping students' determination to enroll in AP course work. Indeed, about four (45\%) out of nine of Latino and $2(100 \%)$ out of 2 of Black participating students attributed their enrollment in math programs, starting in kindergarten, as the most positive influential variable for their entry in calculus courses in high school. This finding suggests that the math experiences in early childhood education most definitely aided these participants' selfefficacy. See figure 1 below.

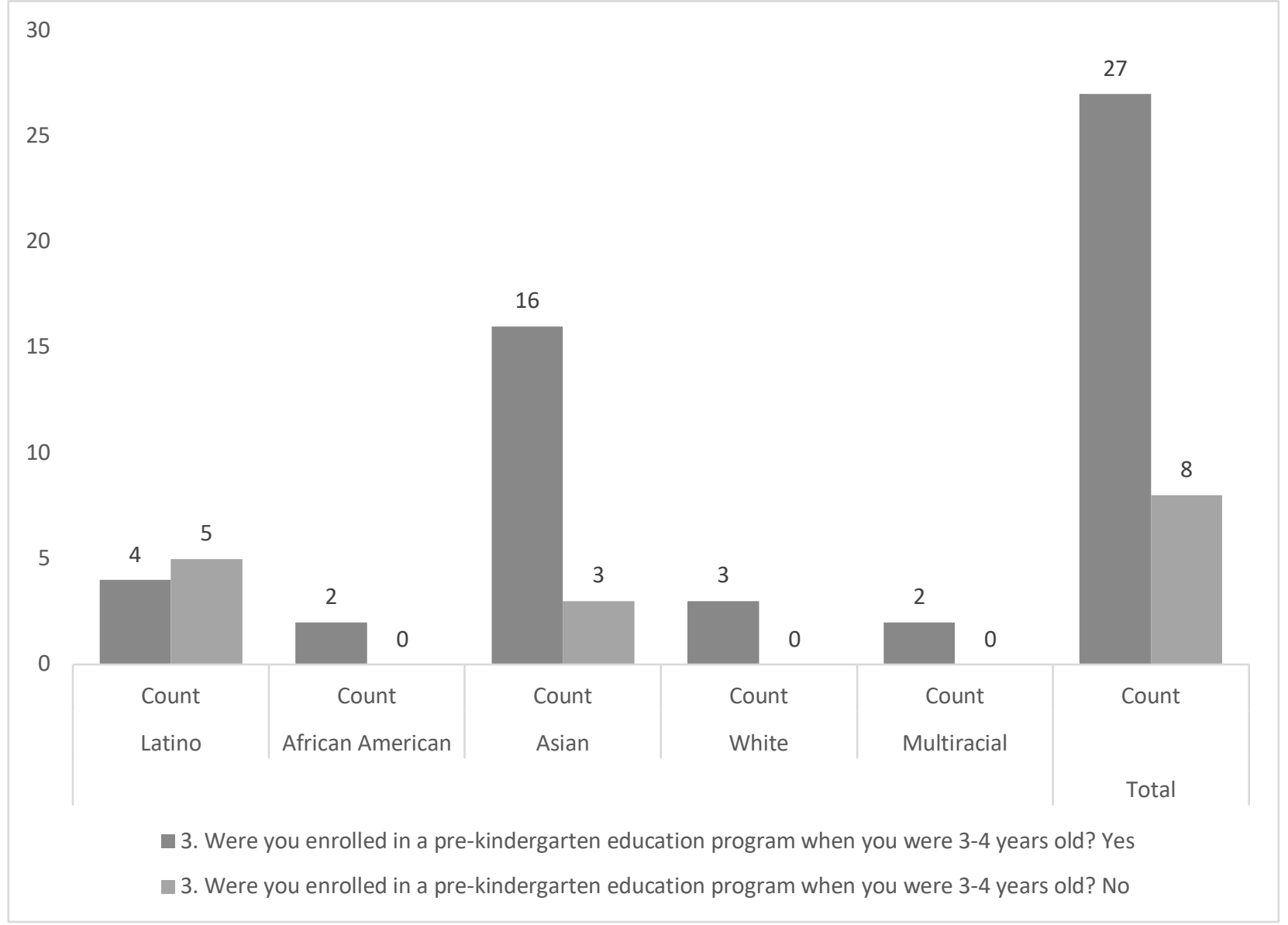

Figure 1. Survey results pre-kindergarten education program.

A significant majority (eight out of nine) of Latino participants (80\%) ranked their math ability as moderate (scale 5-7), while all (100\%) African American participants rated it as high (scale 8-10). See figure 2 below. 


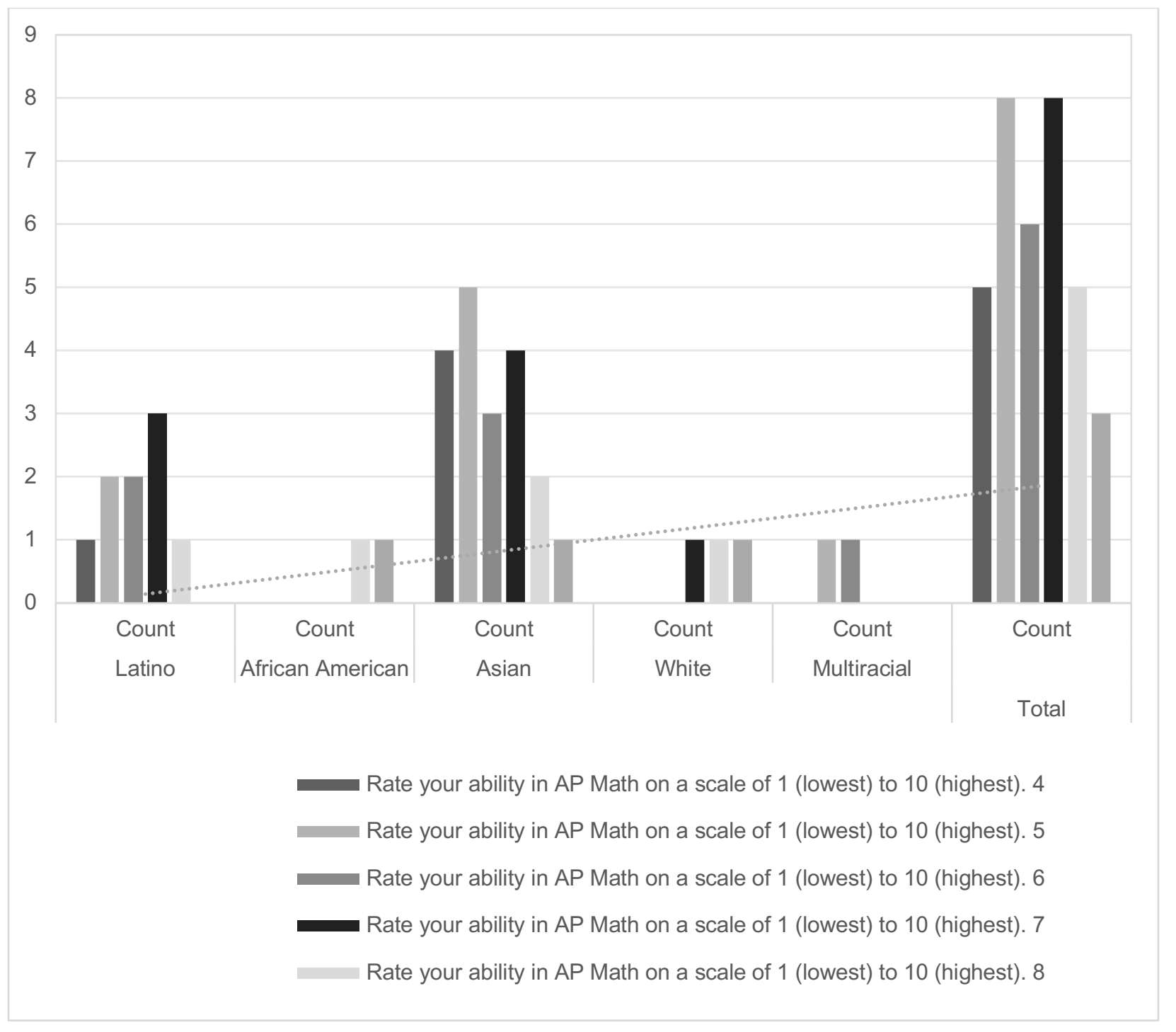

Figure 2. Survey results perceived ability in AP math courses.

As for the importance of math preparation in the middle grades, ratings were higher for both groups. More than half $(56 \%)$ of Latino participants considered it moderate and one third high (33\%), but all (100\%) African Americans rated it high (two out of two). Furthermore, taking pre-calculus courses in high school as a facilitating experience to later enroll in calculus, revealed a similar trend to the middle grades experience. One third (33\%) of moderate, and the other half as high. Latino participants considered it moderate, and almost half (44\%) high; half (50\%) of all African Americans rated it as moderate, and the other half as high. See figure 3 below. 


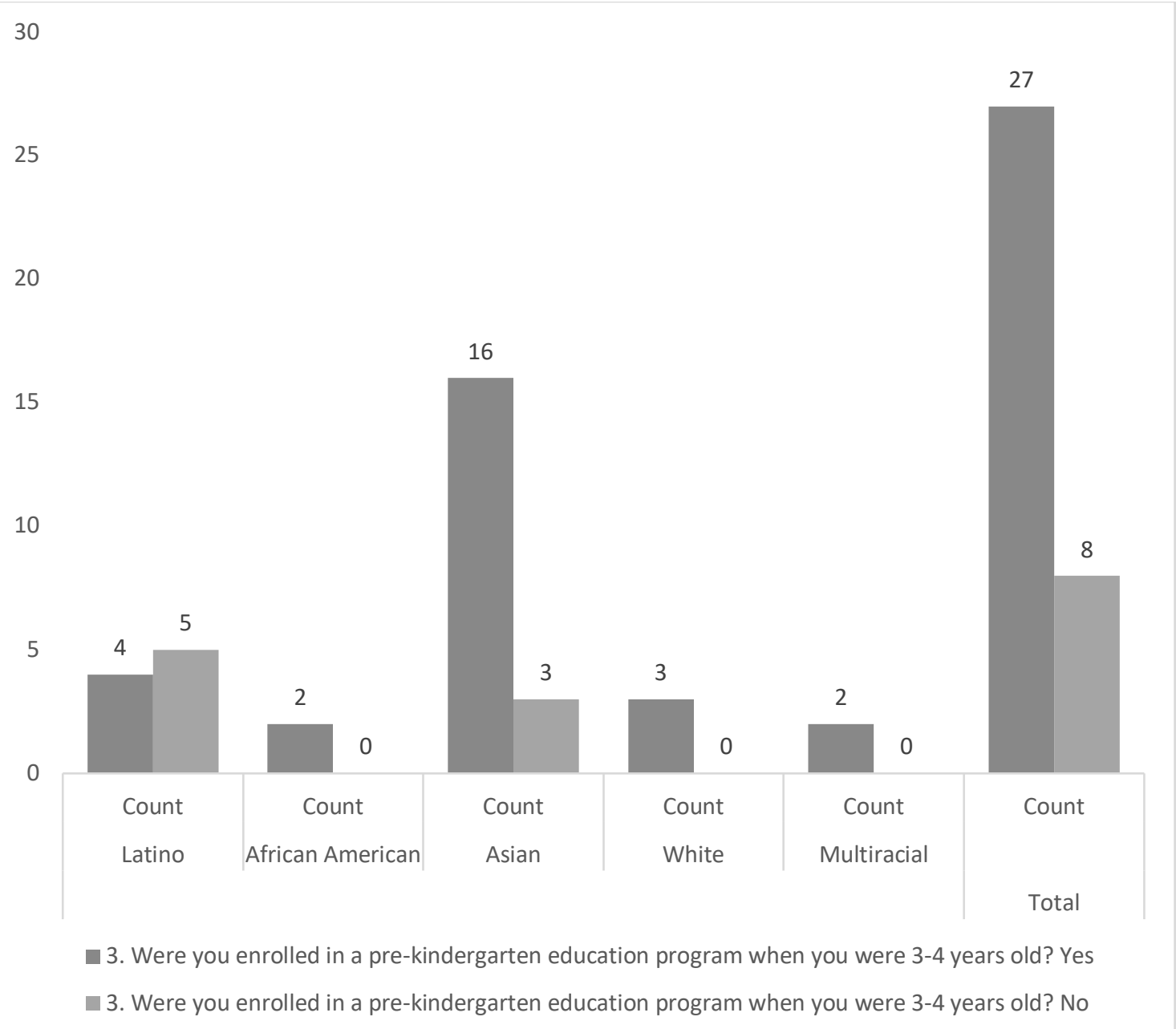

Figure 3. Survey results based on middle school preparation.

Our frequency analysis revealed perceived confidence as the greatest reoccurring factor for both participating groups. This fact stresses the significance of experience given its tight relation to perceived confidence. Data also revealed the relevant role of teachers' agency: confidence pivots on clear explanation of coursework; high expectations, and celebration of success.

We confirmed this pattern throughout our qualitative data. Recalling her middle grades experience, Rosalba captured the important influential role of her math teacher:

I think the best teacher I've had in math, there was my 7th grade teacher, his

name is Mr. W., I would struggle and struggle when I realized what I had

to do is to take it step by step to do the work. I actually got my first "A"

because he helped me. (Interview series, March, 2015).

As Rosalba tells here, the teacher's persistence in her learning the computation process, imprinted an experience that helped build confidence (she earned her first A) and stayed for a long time as a searing cognitive moment. When we interviewed Rosalba, she was in the high track of mathematics in high school. 
Mario's experience resonates with that of Rosalba's. Without naming a specific teacher, he sums up his general positive experience from his early schooling this way:

I went to elementary school in an urban school, which was not the highest

quality, but I was considered a good student, a smart student. (Interview

series, March, 2015)

Mario speaks of the surrounding environment. He knew that adults had framed his participation as good, and personally, as someone intelligent. In such a context Mario seemed to be cognizant that his only option consisted of one thing: high academic performance as a way to meet teachers' expectations.

Benard, an African American youngster, explains teacher's agency in similar terms to the other participants. He says:

My best teacher was in $7^{\text {th }}$ grade, his name was Mr. P. The way

he would teach was calm and he wouldn't teach directly out of the book,

he had his own techniques. The students in that class would

actually understand more than just reading of the paper and trying

to figure out. (Interview series, February, 2015).

Sheena, also African American, refers to the role played by the adults. She extends the positive, gentle cajoling of a teacher to include that of a tutor:

One is Ms. M. and another is a tutor that teaches at Urban

Technical High School, his name is Mr. H. They pushed me.

I started going there at the beginning of the year. They pushed

[me] to do beyond what I thought I could. It takes a lot of

information, a lot of knowledge. They are so good, I don't think

I would be able to do or know what I know now without those

two teachers. (Interview series, February, 2015).

Data also showed that, while peripheral to teachers, parents exerted a persuasive influence in the early grades, and friends in the later ones. This finding confirms Pajares' (2002) study, who found that as students moved through elementary, middle and high school and performed well in math tests and classes, they were likely to develop a strong sense of confidence in their math capabilities, which seemed to only increase from grade level to grade level.

Again, Mario confirmed this fact. Besides naming the positive environment, he stated that his "parents, they always put expectations on me. I wouldn't necessarily say high but they always expected me to do well." (Interview series March 6, 2015). 


\section{CONCLUSION}

We found that experience is the most prominent force influencing African American and Latino students to enroll in AP courses in high school. Of all agents present in their academic experience it is teachers first, and parents secondly, the ones who tend to exert the greatest influence on the decision to take math and science courses. While such influence varies from grade level to grade level, the teachers' central role stayed constant.

Findings revealed that perceived confidence was the greatest reoccurring factor for participants, and that again teachers played a central role in facilitating it. Experience that contributes to the development of confidence is what students in general must be exposed to. In the case of African American and Latino students, this assertion not only becomes magnified but also urgent. To increase the quality and numbers of these two population's entrances into the high track of math and science, and the engineering professions in college, educators ought to pay closer attention and be willing to disrupt these students low-tracking experiences early on.

As with Pajares' (2002) research, our study found that students who perform well on math tests and earn high grades in math classes are likely to develop a strong sense of confidence in their math capabilities. We discovered that confidence seemed to increase as the participants moved from elementary to high school. In other words, positive experience beginning in early childhood education appears to serve as precondition for building self-efficacy in later grades.

Our study is limited in scope - small number of participants - and it is also short in terms of time. Thus, its conclusions may only apply to the schools and the student population directly involved. However, the study points out a possible direction for future research and scholarship in the area of self-efficacy. We posit that the study of modeling and the forging of early constructive experiences may lead to the discovery of pedagogies that will serve all children and youth, but especially Latino and African American children of low socio-economic background. Moreover, the study of the strategic value of modeling as a factor in building self-efficacy, may offer a potential area of professional growth to education leaders in general, and teachers in particular.

\section{REFERENCES}

Archbald, D., Glutting, J., \& Qian, X. (2009). Getting into honors or not: An analysis of the relative influence of grades, test scores, and race on track placement in a comprehensive high school. American Secondary Education, 65-81.

Arellano, A. R., \& Padilla, A. M. (1996). Academic invulnerability among a select group of Latino university students. Hispanic Journal of Behavioral Sciences, 18(4), 485-507.

Bagiati, A., Yoon, S. Y., Evangelou, D., \& Ngambeki, I. (2010). Engineering Curricula in Early Education: Describing the Landscape of Open Resources. Early Childhood Research \& Practice, 12(2), n2.

Bandura, A. (1982). Self-efficacy mechanism in human agency. American psychologist, 37(2), 122.

Bandura, A. (1991). Social cognitive theory of self-regulation. Organizational behavior and human decision processes, 50(2), 248-287.

Bandura, A. (1994). Self-efficacy: Wiley Online Library.

Bandura, A. (2006). Guide for constructing self-efficacy scales. Self-efficacy beliefs of adolescents, 5(307-337). 
Belasco, A. S. (2013). Creating college opportunity: School counselors and their influence on postsecondary enrollment. Research in Higher Education, 54(7), 781-804.

Brenneman, K. (2011). Assessment for Preschool Science Learning and Learning Environments. Early Childhood Research \& Practice, 13(1), n1.

Brown, R., \& Campbell, D. M. (2008). Recent trends in preparing ethnic minorities for careers in mathematics and science. Journal of Hispanic Higher Education.

Brownell, N., Furry, W., \& Beasley, J. (1999). The advanced placement program California's 1997-1998 experience. Institute for Education Reform: Sacramento.

DeJarnette, N. (2012). America's children: Providing early exposure to STEM (science, technology, engineering and math) initiatives. Education, 133(1), 77-84.

Fast, L. A., Lewis, J. L., Bryant, M. J., Bocian, K. A., Cardullo, R. A., Rettig, M., \& Hammond, K. A. (2010). Does math self-efficacy mediate the effect of the perceived classroom environment on standardized math test performance? Journal of educational psychology, 102(3), 729.

Flowers, T. A., \& Flowers, L. A. (2008). Factors affecting urban African American high school students' achievement in reading. Urban Education, 43(2), 154-171.

Gándara, P. (2006). Strengthening the academic pipeline leading to careers in math, science, and technology for Latino students. Journal of Hispanic Higher Education, 5(3), 222-237.

Gándara, P. (2010). The Latino Education Crisis. Educational Leadership, 67(5), 24-30.

Green, C. L., Walker, J. M., Hoover-Dempsey, K. V., \& Sandler, H. M. (2007). Parents' motivations for involvement in children's education: An empirical test of a theoretical model of parental involvement. Journal of educational psychology, 99(3), 532.

Handwerk, P., Tognatta, N., Coley, R. J., \& Gitomer, D. H. (2008). Access to Success: Patterns of Advanced Placement Participation in US High Schools. Policy Information Report. Educational Testing Service.

Hibbs, D. F. (2012). An investigation of the self-efficacy beliefs of Black and Hispanic students that have experienced success or failure in mathematics.

Judge, T. A., Jackson, C. L., Shaw, J. C., Scott, B. A., \& Rich, B. L. (2007). Self-efficacy and work-related performance: the integral role of individual differences. Journal of applied psychology, 92(1), 107.

Kendricks, K. D., \& Arment, A. R. (2011). Adopting A K-12 Family Model With Undergraduate Research To Enhance STEM. Educational Review, 62, 26-44.

Klopfenstein, K. (2004). The advanced placement expansion of the 1990s: How did traditionally underserved students fare? education policy analysis archives, 12, 68.

Lent, R. W., Brown, S. D., \& Hackett, G. (1994). Toward a unifying social cognitive theory of career and academic interest, choice, and performance. Journal of vocational behavior, 45(1), 79-122.

Lichten, W. (2007). Equity and excellence in the College Board Advanced Placement program. Teachers College Record, 6(07). 
Martínez Alemán, A. M. (2006). Latino demographics, democratic individuality, and educational accountability: A pragmatist's view. Educational Researcher, 35(7), 25-31. doi: 10.3102/0013189x035007025

McWayne, C. M., Hahs-Vaughn, D. L., Cheung, K., \& Wright, L. E. G. (2012). National profiles of school readiness skills for Head Start children: An investigation of stability and change. Early Childhood Research Quarterly, 27(4), 668-683.

Murphy, D. S., \& Sullivan, K. (1997). Connecting Adolescent Girls of Color and Math/Science Interventions.

National Center of Education Statistics (2007). The condition of education, 2007. Institute of Education Science. US Department of Education, Washington, DC.

Ndura, E., Robinson, M., \& Ochs, G. (2003). Minority students in high school advanced placement courses: Opportunity and equity denied. American Secondary Education, 21-38.

Nora, A., \& Crisp, G. (2012). Hispanic Student Participation and Success in Developmental Education. White Paper Prepared for the Hispanic Association of Colleges and Universities. Hispanic Association of Colleges and Universities.

Pajares, F. (1996). Self-efficacy beliefs in academic settings. Review of educational research, 66(4), 543-578.

Pajares, F. (2002). Gender and perceived self-efficacy in self-regulated learning. Theory into practice, 41(2), $116-125$.

Pajares, F., \& Kranzler, J. (1995). Self-efficacy beliefs and general mental ability in mathematical problem-solving. Contemporary educational psychology, 20(4), 426-443.

Pape, S. J., \& Wang, C. (2003). Middle school children's strategic behavior: Classification and relation to academic achievement and mathematical problem solving. Instructional Science, 31(6), 419-449.

Pianta, R. C., Belsky, J., Vandergrift, N., Houts, R., \& Morrison, F. J. (2008). Classroom effects on children's achievement trajectories in elementary school. American Educational Research Journal, 45(2), 365-397.

Pomerantz, E. M., Grolnick, W. S., \& Price, C. E. (2005). The role of parents in how children approach achievement. Handbook of competence and motivation, 259-278.

Pungello, E. P., Kainz, K., Burchinal, M., Wasik, B. H., Sparling, J. J., Ramey, C. T., \& Campbell, F. A. (2010). Early Educational Intervention, Early Cumulative Risk, and the Early Home Environment as Predictors of Young Adult Outcomes Within a High-Risk Sample. Child development, 81(1), 410-426.

Ramey, C. T., Campbell, F. A., Burchinal, M., Skinner, M. L., Gardner, D. M., \& Ramey, S. L. (2000). Persistent effects of early childhood education on high-risk children and their mothers. Applied developmental science, 4(1), 2-14.

Rice, K. G., Lopez, F. G., Richardson, C. M., \& Stinson, J. M. (2013). Perfectionism moderates stereotype threat effects on STEM majors' academic performance. Journal of counseling psychology, 60(2), 287.

Rittmayer, A. D., \& Beier, M. E. (2008). Overview: Self-efficacy in STEM. SWE-AWE CASEE Overviews.

Robinson, M. (2003). Student enrollment in high school AP sciences and calculus: How does it correlate with STEM careers? Bulletin of Science, Technology \& Society, 23(4), 265-273.

Rosenbaum, J. E., Miller, S. R., \& Krei, M. S. (1996). Gatekeeping in an era of more open gates: High school counselors' views of their influence on students' college plans. American Journal of Education, 257-279. 
Salzman, H., \& Lowell, B. L. (2007). Into the eye of the storm: Assessing the evidence on science and engineering education, quality, and workforce demand. Quality, and Workforce Demand (October 29, 2007).

Solorzano, D. G., \& Ornelas, A. (2004). A critical race analysis of Latina/o and African American advanced placement enrollment in public high schools. The High School Journal, 87(3), 15-26.

Solorzano, D., \& Ornelas, A. (2002). A critical race analysis of advanced placement classes: A case of educational inequality. Journal of Latinos and Education, 1(4), 215-229.

Trounson, R., \& Colvin, R. (2002). The Nation: Rapid growth of Advanced Placement classes raises concerns. Los Angeles Times.

Usher, E. L. (2009). Sources of middle school students' self-efficacy in mathematics: A qualitative investigation. American Educational Research Journal, 46(1), 275-314.

Usher, E. L., \& Pajares, F. (2006). Sources of academic and self-regulatory efficacy beliefs of entering middle school students. Contemporary educational psychology, 31(2), 125-141.

Usher, E. L., \& Pajares, F. (2008). Sources of self-efficacy in school: Critical review of the literature and future directions. Review of educational research, 78(4), 751-796.

Wang, X. (2013). Why students choose STEM majors motivation, high school learning, and postsecondary context of support. American Educational Research Journal, 0002831213488622.

Whiting, G. W., \& Ford, D. Y. (2009). Multicultural Issues: Black Students and Advanced Placement Classes: Summary, Concerns, and Recommendations. Gifted Child Today, 32(1), 23-26.

Wigfield, A., \& Eccles, J. S. (1994). Children's competence beliefs, achievement values, and general self-esteem change across elementary and middle school. The Journal of Early Adolescence, 14(2), 107-138.

Zarate, M. E., \& Pachon, H. P. (2006). Perceptions of College Financial Aid among California Latino Youth. Policy Brief. Tomas Rivera Policy Institute.

Zeldin, A. L., Britner, S. L., \& Pajares, F. (2008). A comparative study of the self-efficacy beliefs of successful men and women in mathematics, science, and technology careers. Journal of Research in Science Teaching, 45(9), 1036-1058.

Zimmerman, B. J. (2000). Self-efficacy: An essential motive to learn. Contemporary educational psychology, 25(1), 82-91.

Zimmerman, B. J. (2002). Becoming a self-regulated learner: An overview. Theory into practice, 41(2), 64-70.

Zimmerman, B. J., Bandura, A., \& Martinez-Pons, M. (1992). Self-motivation for academic attainment: The role of self-efficacy beliefs and personal goal setting. American Educational Research Journal, 29(3), 663-676.

\author{
About the Author \\ Gilberto Arriaza, Ph.D., Professor, Department of Educational Leadership, California State University, East Bay \\ Cesar Monterrosa, Oakland Unified School District
}

